\title{
MAKNA UPACARA ADAT PEMAKAMAN RAMBU SOLO' DI TANA TORAJA
}

\author{
Anggun Sri Anggraeni ${ }^{1)}$, Gusti Anindya Putri ${ }^{2)}$ \\ Program Studi Desain Komunikasi Visual \\ Fakultas Bahasa dan Seni, Universitas Indraprasta PGRI \\ Jl. Nangka No. 58 C, Tanjung Barat, Jakarta Selatan, 12530, Indonesia \\ anggunanggrainy82@gmail.com
}

\begin{abstract}
Abstrak
Penelitian ini membahas tentang makna upacara adat pemakaman Rambu Solo' bagi masyarakat Tana Toraja. Upacara adat pemakaman Rambu Solo' merupakan ritual upacara adat yang berkaitan dengan kematian seseorang. Tujuannya adalah untuk menghormati arwah atau jiwa seseorang yang meninggal tersebut dan mengantarkannya menuju alam roh atau dapat dikatakan sebagai bentuk penyempurnaan arwah manusia yang telah meninggal. Selain itu, upacara adat pemakaman Rambu Solo' ini juga dilakukan sebagai bentuk pemujaan kepada arwah nenek moyang dan para leluhur mereka. Upacara Rambu Solo' dilakukan oleh masyarakat Toraja atas kepercayaan yang dianut dan berdasarkan dengan tingkatan sosial, serta tahta aturan yang telah ditentukan. Tujuan dilakukannya penelitian ini adalah untuk mengetahui makna dan simbol apa saja yang terkandung dalam upacara adat pemakaman Rambu Solo' serta keterkaitannya terhadap relasi antara Tuhan dengan manusia. Penelitian ini juga bertujuan untuk mengetahui seberapa penting upacara adat pemakaman Rambu Solo' bagi masyarakat Tana Toraja dalam kehidupan mereka. Penelitian ini menggunakan metode pendekatan kualitatif dengan mengumpulkan data sekunder yang berupa hasil penggunaan studi literatur. Kami mengumpulkan informasi dan datadata yang berasal dari sumber buku-buku yang terkait dengan pembahasan objek yang dipilih.
\end{abstract}

Kata kunci: Kebudayaan, Rambu Solo’, Simbol, Toraja, Upacara adat.

\begin{abstract}
This research discusses the meaning of Rambu Solo' funeral rites for the people of Tana Toraja. Funeral Ceremony of Rambu Solo 'is a traditional ceremonial ritual related to someone's death. The purpose is to respect the spirit or soul of someone who died and deliver it to the spirit realm or it can be said as a form of perfecting the spirits of people who have died. In addition, the funeral ceremony for Rambu Solo' was also performed as a form of worship for the spirits of their ancestors. Rambu Solo' Ceremony is performed by the Toraja people for their beliefs and based on social level, as well as the throne of the rules that have been determined. The purpose of this research is to find out what meaning and symbols are contained in the Rambu Solo' funeral rites and their relationship to the relationship between God and humans. This study also aims to find out how important the funeral ceremony for Rambu Solo is for the people of Tana Toraja in their lives. This research uses a qualitative approach by collecting secondary data in the form of the use of literature studies. We collect information and data from sources related to the discussion of selected objects.
\end{abstract}

Keywords: Culture, Rambu Solo', Symbols, Toraja, Traditional ceremonies.

Correspondence author: Anggun Sri Anggraeni, anggunanggrainy82@ gmail.com, Jakarta, and Indonesia 


\section{PENDAHULUAN}

Definisi "kebudayaan" menurut ilmu antropologi adalah keseluruhan sistem gagasan, tindakan dan hasil karya manusia dalam rangka kehidupan masyarakat yang dijadikan milik diri manusia dengan belajar (Koentjaraningrat, 1990: 180). Sedangkan menurut dua orang sarjana antropologi, yaitu A.L. Kroeber dan C. Kluckhohn dalam bukunya yang berjudul Culture, A Critical Review of Concepts and Definitions (1952), kata "kebudayaan" berasal dari kata Sansekerta buddhayah, yang merupakan bentuk jamak dari buddhi yang bermakna "budi" atau "akal". Dengan demikian kebudayaan dapat diartikan sebagai hal-hal yang bersangkutan dengan akal. Demikianlah kata "budaya" bermakna "daya dari budi" yang berupa karsa, cipta dan rasa. Sedangkan kata "kebudayaan" merupakan hasil dari karsa, cipta dan rasa itu.

Dalam setiap daerah yang ditempati oleh penduduk sudah pasti memiliki kebudayaan masing-masing yang berbeda-beda pada tiap daerahnya. Kebudayaan tersebut tercipta berdasarkan interaksi sosial terhadap manusia dan kebiasaan yang dilakukan di lingkungan sekitarnya secara berpola demi mencapai suatu keinginan bersama untuk menjaga kesejahteraan lingkungan masyarakatnya.

Salah satu daerah yang memiliki kebudayaan yang dikenal pada dunia pariwisata adalah Toraja. Toraja merupakan salah satu bentuk suatu wilayah yang terletak di Provinsi Sulawesi Selatan yang memiliki keindahan yaitu antara manusia dan alam terjadi keseimbangan. Masyarakat suku Toraja memiliki anggapan bahwa alam merupakan ciptaan Tuhan yang harus dijaga dan dilestarikan. Hal tersebut juga sebagai suatu bentuk penghormatan kepada arwah para leluhur mereka yang dahulu telah menjaga alamnya dengan baik.

Toraja juga dikenal memiliki banyak kebudayaan di dalamnya. Kebudayaan tersebut tercipta sejak dahulu oleh para leluhur hingga saat ini dan menjadi kebudayaan turun-temurun yang masih dilakukan dan dilestarikan oleh masyarakat suku Toraja. Bentuk kebudayaan yang terkenal di Toraja salah satunya adalah tradisi upacara adat. Upacara adat adalah bentuk suatu permohonan dalam pemujaan, berterima kasih, ataupun pengabdian yang ditujukan kepada kekuasaan-kekuasaan yang luhur, yang menggenggam kehidupan manusia di tangannya (Yusuf, 1993:194). Dalam tradisi upacara adat terdapat ritual-ritual yang merupakan simbol dan masingmasing memiliki makna tersendiri. Mulai dari pakaian, nyanyian, doa, tarian serta benda-benda yang harus ada dalam pelaksanaan ritual upacara adat tersebut.

Pada artikel ini, kami menganalisis tentang upacara adat dari suku Tana Toraja yaitu upacara adat kematian atau Rambu Solo'. Menurut Nugroho (2015:22) Rambu Solo' merupakan ritual upacara adat yang berkaitan dengan kematian seseorang. Tujuannya adalah untuk menghormati arwah atau jiwa seseorang yang meninggal tersebut dan mengantarkannya menuju alam roh atau dapat dikatakan sebagai bentuk penyempurnaan arwah manusia yang telah meninggal.

Upacara adat Rambu Solo' ini juga dilakukan sebagai bentuk pemujaan kepada arwah nenek moyang dan para leluhur mereka. Upacara Rambu Solo' dilakukan oleh masyarakat Toraja atas kepercayaan yang dianut dan berdasarkan dengan tingkatan sosial, serta tahta aturan yang telah ditentukan (Sitonda, 2005:56). Masyarakat Toraja mengenal adanya tiga tingkatan sosial, yaitu bangsawan, orang biasa, dan budak. Selain itu, masyarakat Toraja juga menganut sistem garis keturunan dari pihak wanita atau biasa disebut matrilineal. Jadi, kelas sosial masyarakat suku Toraja ditentukan dan diturunkan melalui garis keturunan ibu.

Tujuan dari penelitian ini adalah untuk mengetahui apa saja makna dan simbol yang terkandung dalam upacara adat kematian Rambu Solo' serta keterkaitannya terhadap relasi antara Tuhan dengan manusia.

\section{METODE PENELITIAN}

Penelitian ini menggunakan metode pendekatan kualitatif dengan mengumpulkan data sekunder. Pendekatan kualitatif biasanya dilakukan dengan cara menjelaskan atau mendeskripsikan suatu objek, menafsirkan dan mengembangkan serta membangun teori dan berorientasi proses. Menurut Sarwono (2017: 17), penelitian sekunder adalah penelitian yang menggunakan data atau informasi yang bukan dari responden sebagai sarana untuk memperoleh 
informasi atau data yang berguna untuk menjawab permasalahan yang diteliti. Penelitian sekunder juga dikenal dengan penelitian yang menggunakan studi kepustakaan atau literatur. Data sekunder tersebut kami cari dan kemudian ditampung menjadi satu kumpulan data yang akan menjadi panduan dalam penelitian objek ini. Metode penelitian yang digunakan adalah deskriptif kualitatif, yaitu mengklasifikasikan data yang diperoleh dari hasil observasi dan kumpulan data literatur yang dijadikan satu lalu disimpulkan yang kemudian disusun secara sistematis yang dibentuk dalam laporan tertulis.

Data sekunder dalam penelitian ini diperoleh dari mencari informasi melalui ensiklopedi, laman web, buku-buku dan artikel jurnal terkait dengan kebudayaan, antropologi dan terutama tentang upacara adat kematian Rambu Solo' yang kemudian akan digunakan sebagai panduan teori bahasan pada penelitian ini.

\section{HASIL DAN PEMBAHASAN}

Dalam sebuah kehidupan di dunia pasti tidak luput dari yang namanya kematian. Semua makhluk yang hidup di bumi, akan mengalami akhir dari sebuah kehidupan dan meninggalkan bumi. Sebuah kehidupan tentu memiliki makna pada masing-masing manusia, begitupun dengan kematian. Setiap manusia memiliki paham yang berbeda dalam memaknai kematian, hal ini berdasar pada budaya di lingkungan yang ada di sekitar orang tersebut. Namun, satu kesamaan dalam paham tersebut adalah manusia menganggap kematian sebagai bentuk perpisahan antar sesame manusia dan memisahkan jiwa dari raga seseorang.

\section{Makna Upacara Adat Pemakaman Rambu Solo'}

Masyarakat Tana Toraja memiliki pandangan bahwa kematian sebagai berpindahnya jiwa seseorang yang telah meninggal dunia menuju ke tempat yang lebih baik yaitu alam roh. Alam roh yang dimaksud adalah kembali pada keabadian bersama para leluhur mereka di sebuah tempat peristirahatan yang bernama Puya. Untuk mencapai tujuan tersebut, masyarakat Toraja melakukan upacara adat pemakaman yang dikenal dengan nama Rambu Solo' dengan cara memperlakukan jasad seseorang dengan sebaik-baiknya. Menurut Nugroho (2015: 22), Rambu Solo' merupakan upacara adat yang berkaitan dengan kematian seseorang yang bertujuan untuk menghormati dan mengantarkan jiwa atau arwah dari seseorang yang telah meninggal dunia menuju alam roh. Selain itu, upacara adat pemakaman Rambu Solo' ini juga dilakukan sebagai bentuk pemujaan pada arwah nenek moyang dan leluhur mereka. Sitonda (2005: 56) dalam bukunya menyebutkan bahwa upacara adat pemakaman Rambu Solo' ini dilakukan oleh masyarakat Toraja berdasar atas kepercayaan yang dianut dan juga atas dasar tingkatan atau strata sosial, dan tahta aturan yang telah ditentukan. Strata sosial yang ada pada masyarakat Tana Toraja dikenal empat macam tingkat, di antaranya adalah 1) Tana' Bulaan yaitu golongan bangsawan, 2) Tana' Bassi yautu golongan bangsawan menengah, 3) Tana' Karurung yaitu rakyat biasa, dan

4) Tana Киа-Киа yaitu golongan hamba atau kurang mampu (Marampa, 2003: 48).

Upacara adat pemakaman Rambu Solo' dapat dikatakan sebagai kegiatan pelaksanaan ritual yang sangat penting dan berbiaya tinggi. Dengan adanya aturan pelaksanaan upacara yang disesuaikan dengan strata sosial, maka dapat memberikan ciri-ciri yang khas pada pelaksanaan upacara adat pemakaman Rambu Solo' ini.

Seperti yang dikatakan oleh Nugroho dalam bukunya yang berjudul Kebudayaan Masyarakat Toraja (2015: 22-23) menyebutkan bahwa tingkatan yang ada pada upacara pemakaman Rambu Solo' di antaranya adalah:

1. Dipasang Bongi, yaitu upacara pemakaman yang dilaksanakan hanya dalam semalam saja.

2. Dipatallung Bongi, yaitu upacara pemakaman yang berlangsung hingga tiga malam yang dilaksanakan di kediaman almarhum serta melakukan pemotongan hewan

3. Dipalimang Bongi, yaitu upacara pemakaman yang berlangsung hingga lima malam yang dilaksanakan di kediaman almarhum serta melakukan pemotongan hewan

4. Dipapitung Bongi, yaitu upacara pemakaman yang berlangsung hingga tujuh malam atau satu minggu penuh yang di setiap harinya melakukan pemotongan hewan 
5. Upacara Tertinggi, upacara ini biasanya dilakukan dua kali dalam rentang waktu sekurangkurangnya satu tahun. Upacara pertama disebut Aluk Pia dan upacara kedua disebut Rante. Upacara Aluk Pia bertempat di sekitar Tongkonan keluarga yang berduka, sedangkan upacara Rante dilaksanakan di sebuah lapangan khusus karena upacara Rante ini merupakan upacara puncak prosesi pemakaman.

Menurut L.T. Tangdilintin (1980: 125-133), upacara adat pemakaman Rambu Solo' dibagi ke dalam empat tingkatan, di mana pada setiap tingkatan juga memiliki beberapa bentuk. Keempat tingkatan tersebut adalah sebagai berikut:

1. Upacara Disilli' yaitu upacara pemakaman yang paling rendah di dalam Aluk Todolo (kepercayaan leluhur), diperuntukkan bagi pemakaman dengan strata yang paling rendah (Tana' Kua-Kua) atau anak-anak yang belum memiliki gigi (bayi dan balita).

2. Upacara Dipasangbongi yaitu upacara pemakaman yang berlangsung hanya satu malam. Upacara Dipasangbongi ini diperuntukkan bagi kelompok strata rakyat biasa (Tana' Karurung), tetapi bisa juga dilakukan oleh orang dari strata Tana' Bulaan dan Tana' Bassi jika mereka tidak mampu secara ekonomi.

3. Upacara Dibatang atau Didoya Tedong yaitu upacara pemakaman yang setiap harinya menambatkan satu ekor kerbau pada sebuah patok dan dijaga oleh orang sepanjang malam tanpa tidur. Selama upacara Dibatang ini berlangsung, setiap harinya diadakan pemotongan satu ekor kerbau. Upacara adat pemakaman ini diperuntukkan bagi strata bangsawan menengah (Tana' Bassi), tetapi juga bisa dilakukan oleh kaum bangsawan tinggi (Tana' Bulaan) yang tidak mampu membuat upacara Rapasan.

4. Upacara Rapasan yaitu upacara yang dilaksanakan sebanyak dua kali. Upacara Rapasan ini diperuntukkan bagi kaum strata bangsawan tinggi (Tana' Bulaan). Upacara Rapasan ini memiliki tiga jenis didalamnya, seperti:

a. Upacara Rapasan Diongan atau Didandan Tana' yang berarti di bawah, atau menurut syarat minimal. Pemotongan kerbau sekurang-kurangnya ada sembilan ekor dan babi sebanyak yang dibutuhkan/sebanyak-banyaknya. Upacara Rapasan Diongan ini dilaksanakan selama tiga hari di halaman Tongkonan (rumah adat suku Toraja), upacara pertama ini disebut dengan Aluk Pia atau Aluk Banua. Kemudian upacara kedua dilaksanakan di Rante (lapangan), upacara kedua ini disebut dengan Aluk Palao atau Aluk Rante

b. Upacara Rapasan Sundun atau Doan yang berarti upacara sempurna/atas. Pemotongan kerbau sekurang-kurangnya adalah dua puluh empat ekor dan jumlah babi yang tidak terbatas untuk dua kali pelaksaan pesta. Upacara ini dikhususkan untuk bangsawan tinggi yang kaya, atau para pemangku adat. Pelaksanaan upacara ini sama seperti upacara Rapasan Diongan.

c. Upacara Rapasan Sapu Randanan yang berarti serata dengan tepi sungai. Pemotongan kerbau pada upacara ini sangat melimpah, karena ada yang mengatakan jumlah kerbau di atas dua puluh empat ekor, di atas tiga puluh ekor, bahkan ada juga yang menyebutkan di atas seratus ekor kerbau. Pada upacara ini, masyarakat menyiapkan Duba-Duba (tempat pengusungan mayat, mirip dengan Tongkonan) dan juga Tau-Tau (patung dari orang yang meninggal, yang kemudian diarak bersama dengan jasad orang tersebut ketika akan dilaksanakan Aluk Rante.

\section{Simbol-Simbol pada Upacara Adat Pemakaman Rambu Solo'}

Menurut Budiman (2011: 22), simbol merupakan jenis tanda yang bersifat arbiter dan konvensional. Simbol merupakan tanda bahasa yang dapat mewakili bentuk komunikasi verbal ataupun non-verbal yang terdapat dalam tradisi budaya dan dijadikan sebagai alat untuk mempertahankan tradisi kebudayaan masyarakat. Upacara adat pemakaman Rambu Solo' memiliki dua jenis simbol yang digunakan dalam pelaksanaan ritualnya, yaitu simbol verbal dan non-verbal. 


\title{
Simbol Verbal
}

Seperti yang dikutip oleh Embon (2018: 4-5), simbol verbal atau bahasa lisan yang terdapat pada upacara Rambu Solo' berupa doa-doa yang diucapkan pada saat pelaksanaan ritual dan bentuknya seperti:

1. Doa Permohonan Perlindungan

Doa permohonan perlindungan ini berisi permohonan atau berserah diri kepada Puang Matua agar diberi perlindungan dan kehidupan yang baik serta layak untuk manusia. Doa ini juga sebagai ucapan syukur karena telah diberikan kenikmatan hidup di dunia termasuk yang telah meninggal serta bagi keluarga yang ditinggalkan. Bentuk ucapan doa permohonan perlindungan adalah seperti:

Sola passulean allo

Angki rampo tumangke suru'

Angki petunda tomammaki

Matik tangngana langik

Angki paruyang tomatindomo

Matik inanna topalullungan

Umpennoloan mintu sarak tengka ke'deki

\author{
Artinya: \\ Bersama bergantinya hari \\ Kami dating menyembah Tuhan \\ Kami bersama berseru kepadaMu \\ Ke dalam tempat yang Maha Tinggi \\ Kami bersama bersembah sujud \\ Untuk menyerahkan seluruh kehidupan
}

2. Doa Pengagungan Kepada Leluhur

Doa ini berisi permohonan dan pujian kepada To Dolo agar tetap mengizinkan muka bumi ditempati oleh manusia dan tetap memberikan kesuburan tanah untuk kemakmuran manusia secara turun-temurun. Bentuk ucapan doa pengagungan kepada leluhur adalah seperti:

To dolo kaubanan dao masuanggana topalullungan

To dolo dao ba'ba manikna, dao gaun ma'gulung-gulunganna

\section{Artinya:}

Mereka yang terdahulu beruban yang bertahta di atas tempat tinggi

Mereka yang terdahulu bersemayam di pintu kerajaan di atas awan

Tondok mariri litakna

Kemasak pellaoanna

Malangka ongan banuanna

\author{
Artinya: \\ Negeri bertambah kuning \\ Bercahaya manik-manik \\ Pelindung rumahnya sangat tinggi
}

3. Doa Kepada Orang yang Wafat Agar Arwahnya Diterima

Doa ini berisi tentang gambaran seorang bangsawan yang lahir dari sebuah tongkonan secara turun-temurun. Dari tongkonan itu telah lahir pemimpin, penguasa atau pemangku adat yang memiliki kekuasaan dalam memerintah dan mengayomi banyak orang 
(To Parengnge') yang didoakan agar arwahnya diterima oleh Yang Maha Kuasa. Bentuk doa kepada orang yang wafat agar arwahnya diterima adalah seperti:

\section{Ambekta urrinding lembong \\ Umpayo-payo tondok \\ Umbangunan biang rakba \\ Untuklak tille malulun}

\section{Artinya:}

Ayah kita yang menaungi kampong

Memelihara Negeri ini

Menegakkan gelagah rebah

Menopang pimping yang miring

Mario-rio matarampak

Songka kami barana'ki

Tibambang kami lamba' $k i$ '

Todilolloan dao mai tongkonan layuk

To dipamadatu muane esungan pa 'kalandoanna pa'tala baine

Tongkonan peseoaluk tambakuku

\section{Artinya:}

Rasa sedih sekeliling rumah

Beringin kami telah tumbang

Pohon tinggi kami telah terbanting

Orang yang dihormati kedudukannya baik laki-laki maupun perempuan

Tongkonan pemangku adat kuat dan kokoh

Anna puang matua mora

La sumpu mamase liu kaboro'

Tarru' lamakari tutu

Lako batang ri kalena

\section{Artinya:}

Tuhanlah saja yang akan memberi kasih sayang

Sangat memelihara

Kepada dirinya

\section{Simbol Non-Verbal}

Bentuk komunikasi non-verbal merupakan proses komunikasi yang dalam penyampaian pesannya tidak menggunakan pengucapan atau kata-kata, melainkan menggunakan bahasa isyarat, gerakan tubuh (bahasa tubuh), ekspresi wajah, kontak mata, penggunaan objek seperti pakaian, potongan rambut dan lainnya.

Dalam melaksanakan upacara Rambu Solo', peralatan-peralatan yang digunakan dalam ritual upacara memiliki makna tersendiri dan merupakan bentuk dari simbol non-verbal. Peralatan-peralatan tersebut antara lain adalah:

1. Gandang (Gendang)

Gandang merupakan sebuah gendang yang dipukul sebagai pengatur dan tanda peralihan acara pemakaman. Gandang bermakna agar upacara yang berlangsung menjadi semakin meriah. 


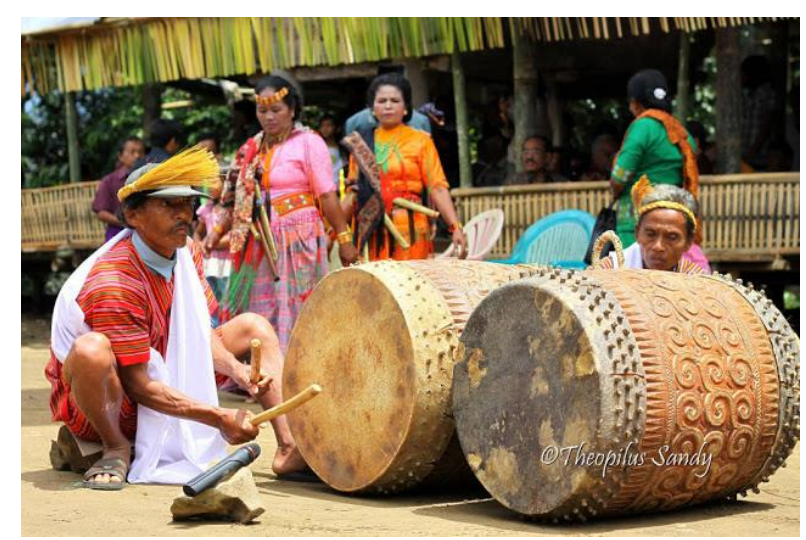

Gambar 1. Gandang (gendang)

2. Tombi (Bendera)

Tombi merupakan kain panjang yang seragam yang dibawa oleh keluarga dan panjangnya disesuaikan dengan kebutuhan. Tombi memiliki makna keagungan dan ketinggian upacara pemakaman dan hanya digunakan oleh para Tana' Bulaan.

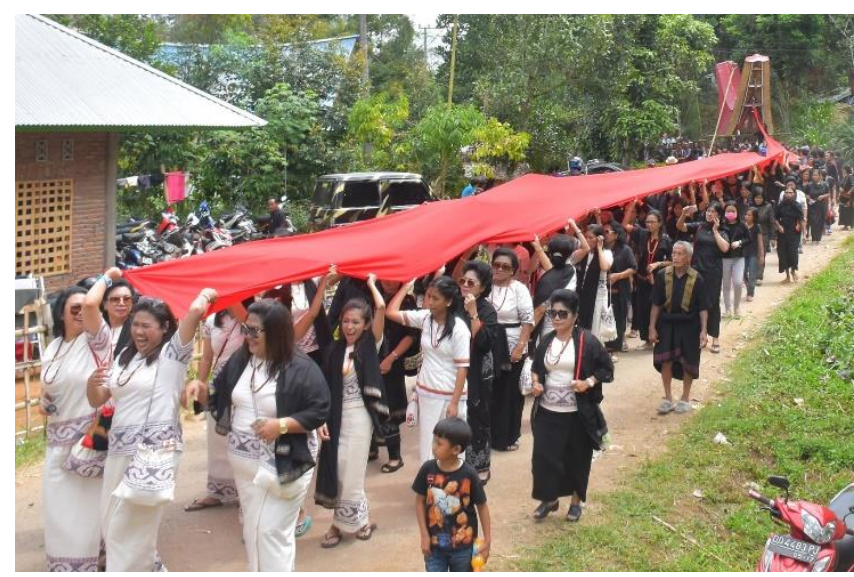

Gambar 2. Tombi (bendera)

3. Bombongan (Gong)

Bombongan merupakan gong yang ditabu pada saat upacara berlangsung. Bombongan memiliki makna tangis kepiluan bagi keluarga-keluarga bangsawan Toraja.

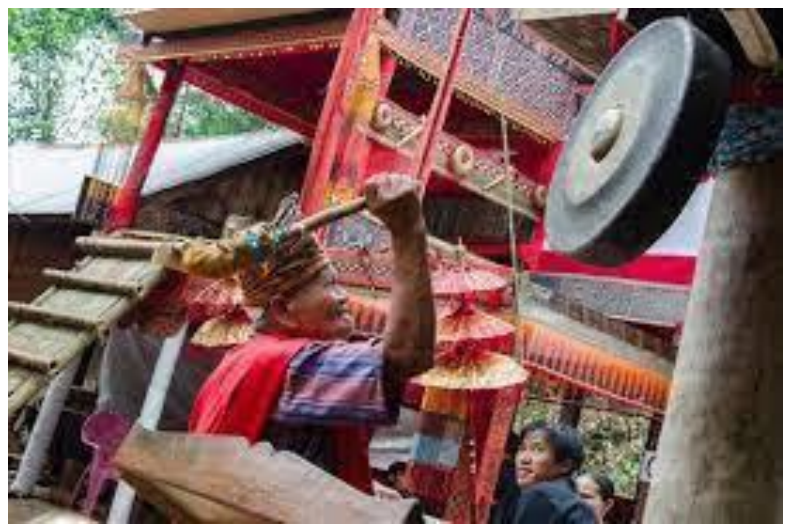

Gambar 3. Bombongan (gong) 
4. Sesaji

Sesaji merupakan makanan yang disajikan oleh keluarga yang ditinggalkan kepada orang yang sudah meninggal. Mereka memberikan sesaji karena mereka percaya bahwa arwah orang yang meninggal masih berkeliaran di sekitar rumahnya.

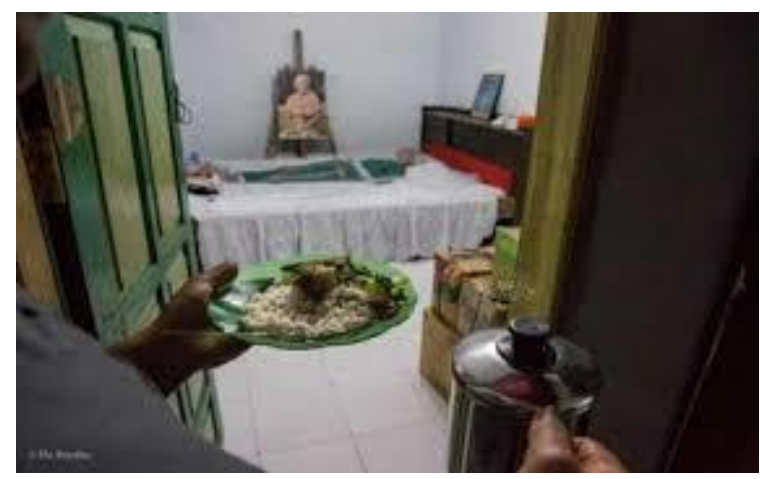

Gambar 4. Sesaji

5. Maa

Maa merupakan kain berukir yang digunakan untuk membungkus kerbau untuk mengarak mayat, membungkus peti mati, dan menghias lantang. Maa memiliki makna sebagai tanda kemuliaan dan keagungan dari orang Toraja.

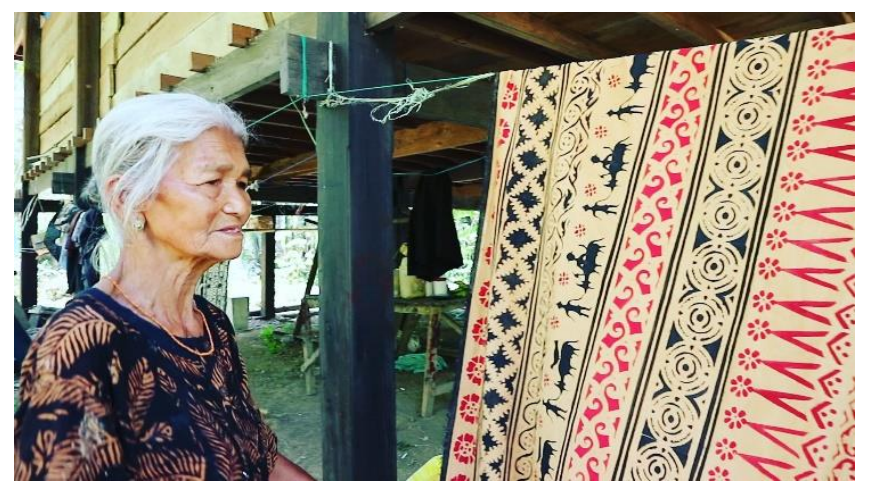

Gambar 5. Maa

6. Hewan Kurban

Hewan kurban yang digunakan pada upacara Rambu Solo' adalah kerbau dan babi, karena dianggap memiliki nilai yang tinggi di kalangan masyarakat Toraja. Banyaknya jumlah kerbau yang dikurbankan pada saat upacara menandakan bahwa orang yang meninggal dan keluarga yang ditinggalkan merupakan kalangan bangsawan. Kerbau yang telah dikurbankan dipercaya sebagai hewan yang ditunggangi oleh arwah orang yang meninggal. Sedangkan babi digunakan sebagai kurban atas rasa syukur kepada Tuhan. 


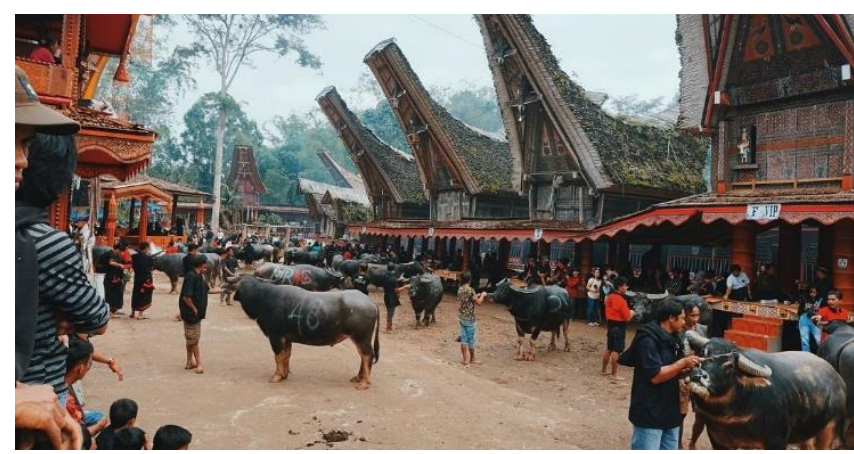

Gambar 6. Hewan Kurban

\section{Kuang-Kuang}

Kuang-kuang merupakan tanda upacara yang diletakkan di depan pada saat upacara Aluk Todolo yang menganut ajaran turun-temurun dalam membina arwah leluhur pada empat penjuru alam dan juga diajukan untuk para bangsawan di Tana Toraja. Kuang-kuang berupa bambu yang disusun dan dihias dengan hiasan-hiasan Toraja, dan menggunakan bulu ayam. Kuang-kuang memiliki makna melambangkan strata atau tingkatan atas dan dipasang sebelum memotong hewan kurban pada saat upacara berlangsung.

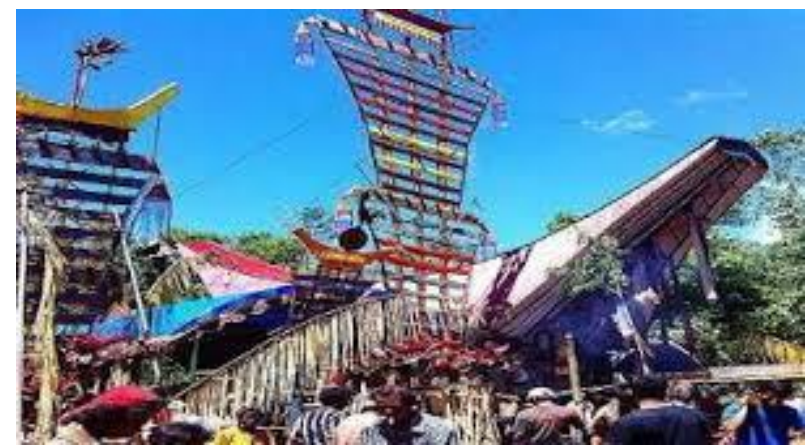

Gambar 7. Kuang-kuang

\section{SIMPULAN}

Masyarakat suku Toraja memiliki anggapan bahwa alam merupakan ciptaan Tuhan yang harus dijaga dan dilestarikan. Hal tersebut juga sebagai suatu bentuk penghormatan kepada arwah para leluhur mereka yang dahulu telah menjaga alamnya dengan baik. Toraja juga dikenal memiliki banyak kebudayaan di dalamnya. Kebudayaan tersebut tercipta sejak dahulu oleh para leluhur hingga saat ini dan menjadi kebudayaan turun-temurun yang masih dilakukan dan dilestarikan oleh masyarakat suku Toraja. Bentuk kebudayaan yang terkenal di Toraja salah satunya adalah tradisi upacara adat. Masyarakat Tana Toraja memiliki pandangan bahwa kematian sebagai berpindahnya jiwa seseorang yang telah meninggal dunia menuju ke tempat yang lebih baik yaitu alam roh. Alam roh yang dimaksud adalah kembali pada keabadian bersama para leluhur mereka di sebuah tempat peristirahatan yang bernama Puya. Upacara adat pemakaman Rambu Solo' dapat dikatakan sebagai kegiatan pelaksanaan ritual yang sangat penting dan berbiaya tinggi. Karena dengan adanya aturan pelaksanaan upacara yang disesuaikan dengan strata sosial, maka dapat memberikan ciri-ciri yang khas pada pelaksanaan upacara adat pemakaman Rambu Solo' ini. 


\section{DAFTAR PUSTAKA}

Budiman, K. (2003). Semiotika visual konsep, isu, dan problem ikonisitas. Yogyakarta: Jalasutra.

Embon, D., \& Saputra, I. G. K. A (2018). Sistem simbol dalam upacara adat Toraja Rambu Solo: Kajian semiotik. Jurnal Bahasa dan Sastra, 3(7).

Koentjaraningrat. (1990). Pengantar ilmu antropologi. Jakarta: Rineka Cipta.

Marampa, A.T. (2003). Guide to Tana Toraja.

Nugroho, F. (2015). Kebudayaan Masyarakat Toraja. Surabaya: JePe Press Media Utama.

Sarwono, J. (2017). Metodologi penelitian kuantitatif dan kualitatif. Edisi Pertama. Yogyakarta.

Sitonda, M. N. (2005). Toraja warisan dunia. Makassar: Pustaka Refleksi.

Tangdilintin, L.T. (1980). Toraja dan kebudayaannya. Tana Toraja: Yayasan Lepongan Bulan.

Yusuf, W. P. (1993). Upacara tradisional (upacara kematian) daerah Sulawesi Selatan. Jakarta: Departemen Pendidikan dan Kebudayaan. Direktorat Jenderal Kebudayaan, Proyek Penelitian, Pengkajian dan Pembinaan Nilai-nilai Budaya Sulawesi Selatan. 